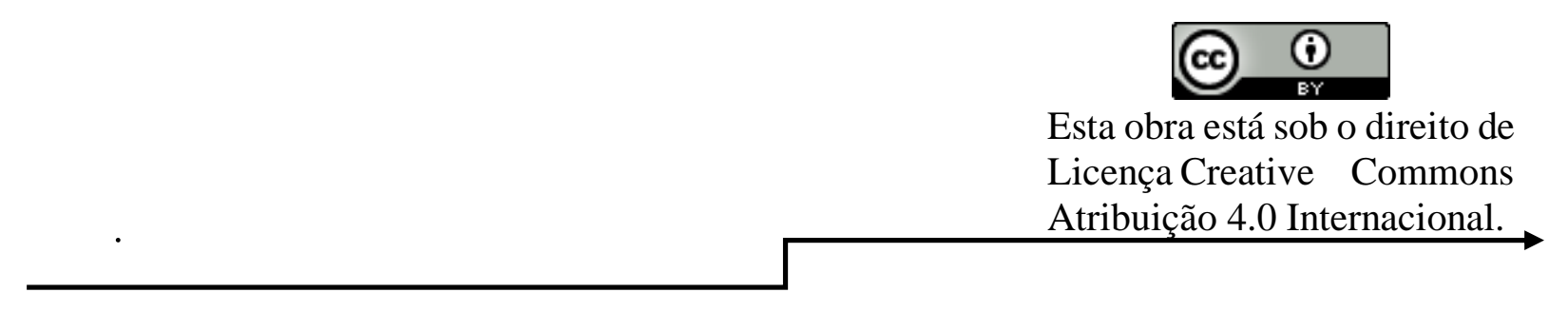

\title{
A LUDICIDADE NA ESCOLA: PERSPECTIVAS EDUCATIVAS PARA A PROFISSÃO DOCENTE
}

Fabia de Oliveira Silva ${ }^{1}$

Aline Pereira Barros ${ }^{2}$

Maria Angela da Silva Alves ${ }^{3}$

Wilamo de Omena Lopes Junior ${ }^{4}$

\section{RESUMO}

Os efeitos do brincar começam a ser investigados pelos pesquisadores que consideram a ação lúdica como metacomunicação, ou seja, a possibilidade da criança compreender o pensamento e a linguagem do outro. Portanto, o brincar implica uma relação cognitiva e representa a potencialidade para interferir no desenvolvimento infantil, além de ser um instrumento para a construção do conhecimento do aluno. O objetivo deste trabalho é observar alguns tópicos que nortearam a escolha do tema e do problema principal: por que as crianças brincam e de que forma? Qual a relação do lúdico no processo de ensino e aprendizagem? E como o lúdico, por meio da formação do educador, interfere neste processo? Inclui um vasto estudo teórico a respeito das estratégias voltadas para o conceito histórico de criança, concepção sobre o cuidar, fundamentos sobre as instituições escolares e aborda o tema principal sobre conceitos de ludicidade e estudiosos que defendem este novo prazer lúdico como um de diversos instrumentos que podem ser contextualizados e que influenciam no desenvolvimento cognitivo e social dos educandos, agindo de forma dinâmica na relação de educandos e educadores no processo de ensino e aprendizagem. Viram-se atividades nas quais foram observados conteúdos que envolvessem as brincadeiras lúdicas e que confirmam que as crianças aprendem com mais facilidade brincando. No entanto, a ludicidade ajuda no aprimoramento da educação, pode ser crítica e criativa, de acordo com a demanda e realidade da sala de aula e, junto ao educador, desenvolve possibilidades que permitam aos educandos a experimentar situações que interferem no ensino bem como a importância de um educador mediando esta relação de ensino e aprendizagem com a ludicidade. Diante do pesquisado foi possível verificar a necessidade de mudanças de metodologia de ensino, pois a atividade lúdica é pouco explorada devido a fatores externos de administração como ausência de planejamento, de meios e instrumentos de trabalho. Sugerimos, para pesquisas posteriores, alavancar o universo do lúdico com outras disciplinas, assim como realizar um estudo comparativo com outras séries entre as escolas do

\footnotetext{
1 fabia.oliveira1@gmai.com

2 aline_barros09@hotmail.com

3 angelateacher2@hotmail.com

4 wiliamojr@msn.com
} 
município e ainda uma avaliação com a aplicação do lúdico com docentes e discentes a fim de confrontar os resultados.

Palavras-chave: Aprendizagem. Lúdico. Estratégia. 


\section{INTRODUÇÃO}

Percebe-se que os educadores da atualidade precisam utilizar-se do lúdico na educação infantil, pois ao separar o mundo adulto do infantil, e ao diferenciar o trabalho da brincadeira, a humanidade observou a importância da criança que brinca.

Desta forma, a escola deve facilitar a aprendizagem utilizando-se de atividades lúdicas que criem um ambiente alfabetizador para favorecer o processo de aquisição de autonomia de aprendizagem. Para tanto, o saber escolar deve ser valorizado socialmente e a alfabetização deve ser um processo dinâmico e criativo através de jogos, brinquedos, brincadeiras e musicalidade.

$\mathrm{Na}$ utilização de jogos, para desenvolver habilidades de leitura e escrita é necessário considerar situações em que o ler e o escrever tenham um significado para o aluno. Cabe ressaltar, então, as diferenças entre letramento e alfabetização já que nem sempre o indivíduo sabe que a escrita "representa" a fala. Esse indivíduo além de saber ler e escrever tem que ser letrado, ou seja, entender o que se está lendo, interpretar.

O letramento está diretamente relacionado ao ensino da leitura e escrita: algumas pessoas até podem ser alfabetizadas - aprendem a ler e escrever porém, não necessariamente incorporam a prática da leitura e da escrita. É preciso, então, considerar que apesar de conceitos distintos a alfabetização é uma etapa do letramento.

O desenvolvimento da leitura e escrita desperta atenção pela importância que desempenha em todo o processo educativo.

A utilização de jogos no processo de letramento possibilita a aproximação dos usos e funções da leitura e escrita no cotidiano do aluno numa aprendizagem significativa. Lembrando também que os jogos proporcionam o aprender de forma prazerosa, num contexto desvinculado da situação de aprendizado formal.

Os jogos, os desenhos e brincadeiras de faz-de-conta, sem dúvida são meios facilitadores na descoberta da leitura e escrita: profissionais da área educacional, comprometidos com a qualidade da sua prática pedagógica e/ou psicopedagógica, reconhecem a importância dos jogos como veículo para o desenvolvimento social, emocional e intelectual dos alunos.

Vale ressaltar que o propósito deste estudo se restringe à utilização somente dos jogos (diferenciados dos desenhos e demais brincadeiras) no 
processo de letramento (já considerando suas diferenças com a alfabetização).

Através do jogo o indivíduo pode brincar naturalmente, testar hipóteses, explorar toda a sua espontaneidade criativa. Os jogos não são apenas uma forma de divertimento: são meios que contribuem e enriquecem o desenvolvimento intelectual. Para manter seu equilíbrio com o mundo a criança precisa brincar, criar e inventar. A criança devota ao jogo a maior parte do seu tempo. Com jogos e brincadeiras, a criança desenvolve o seu raciocínio e conduz o seu conhecimento de forma descontraída e espontânea: no brincar, ela constrói um espaço de experimentação, de transição entre o mundo interno e externo.

Esta pesquisa foi elaborada através de reflexões teóricas (principais aspectos do letramento; utilização dos jogos centrada na aprendizagem da escrita e leitura; o jogo no processo educativo e psicopedagógico) e ilustrada com relatos de caso.

A razão para o desenvolvimento deste estudo surgiu já no decorrer do curso de pós-graduação em Psicopedagogia no

\section{REFERENCIAL TEÓRICO}

\section{Um olhar sobre a educação infantil}

Na fase infantil há só uma obrigação da vida das crianças que é a de frequentar a escola, aprenderem a ler e a escrever, a ansiedade e a expectativa dos pais e da qual se evidenciou um número expressivo de crianças com dificuldades de aprendizagem, relacionadas à leitura e escrita no contexto escolar.

Durante o estágio clínico supervisionado, o espaço e tempo utilizados para a criança brincar e, assim melhor se comunicar, revelou-se imprescindível para as relações vinculares e construção do conhecimento. Deste modo, perceber que os jogos contribuem para o aprendizado foi inevitável.

Só será possível ensinar e aprender prazerosamente quando compreendermos melhor nossas crianças. Antes de frequentar a escola, elas vivem o seu mundo real. $\mathrm{O}$ desejo ou a paixão de conhecer tudo em volta de si faz de seus movimentos e brincadeiras, seu mais sério meio de apropriar-se do mundo e de comunicar-se com ele. Porém, ao chegar à escola, a criança encontra uma realidade diferente da sua, a qual anula tudo aquilo que representa sua forma de viver, compreender e apropriar-se de seu contexto sociocultural.

sociedade para que isto aconteça é grande. Porém é uma frustração para as crianças quando começam a perceber que vai ficando difícil aprender a ler e a escrever e não conseguirem atingir estes objetivos que são traçados e esperados. É importante nesse momento de angústia por parte dos 
pais e dos alunos que não conseguem acompanhar o currículo normal da escola, que os pais e os professores comecem um processo de investigação sobre as possíveis causas desse processo.

Definir leitura e escrita não é uma em uma atividade fácil, são vários os sentidos que podem ser atribuídos às ideias de leitura e escrita, podendo estes, serem restritos ou amplos. Em termos escolares, tanto a leitura quanto a escrita estão diretamente vinculadas à alfabetização, adquirindo deste modo caráter de aprendizagem formal.

Quando um aluno não consegue aprender de forma natural os conteúdos e atividade proposta em sala de aula é logo rotulada como aluno problema, é aquele que não consegue aprender, não se concentra em sala de aula e por ficar sem atividade acaba atrapalhando os colegas e tirando do sério o professor. Mas é preciso entender que vários fatores levam uma criança a não aprender de forma convencional e os transtornos ou distúrbios evidenciam isso no fator educacional. Um desses transtornos é a dislexia.

É de grande importância afirmar que a leitura e a escrita são atividades fundamentais para o desenvolvimento e formação de qualquer indivíduo, pois dentro e fora da escola e por toda vida, o domínio da leitura e da escrita facilitará ou não o crescimento intelectual, pessoal, profissional e de mundo.

Segundo Smith (2001), dificuldades de aprendizagem (D.A.) são "problemas neurológicos que afetam a capacidade do cérebro para entender, recordar ou comunicar informações". Considera-se que, tem-se estudado muito sobre o tema, mas as informações obtidas penetram no âmbito educacional de forma lenta. Assim, as dificuldades de aprendizagem referem-se não a um único distúrbio, mas a uma ampla gama de problemas que podem afetar qualquer área do desempenho escolar. Raramente, elas podem ser atribuídas a uma única causa, e muitos aspectos diferentes podem prejudicar o funcionamento cerebral, até o ambiente doméstico contribui para isso.

A escola, enquanto espaço de construção e formação do saber tem a função de proporcionar momentos de questões respostas para gerar uma descoberta sobre algo. Já o professor, enquanto mediador da aprendizagem tem, como uma de suas funções, investigar a dúvida, provocar o educando para a indagação do que anseia aprender e mostrar-lhe que há várias fontes de saber.

Tavares (1996, p.34), considerando também este contexto, afirma que:

O professor ajude os alunos a estabelecer relações entre o que já 
aprenderam e o que estão aprendendo, criando em sala de aula um ambiente favorável à troca de ideias. Isso significa que os professores devem constantemente propor questões que possibilitem aos alunos refletir sobre o que sabem e o que estão aprendendo. Outras vezes, é o professor quem explicita as relações de que ele pode estabelecer entre um conhecimento e outro. As perguntas e as relações verbalizadas ajudam os alunos a perceber que a construção do conhecimento ocorre por meio de sucessivas reorganizações, as quais são feitas a partir de novas relações.

Valorizar o que ao aluno já conhece sobre determinado conteúdo ou tema abordado em sala de aula é o ponto de partida para que o professor avalie o nível de conhecimento e de interação da criança no grupo, é importante reconhecer que o conhecimento é socialmente construído e que a escola vai oportunizando o sujeito a organizar os seus pensamentos, fazendo com que o mesmo tenha uma visão crítica sobre aquilo que já conhece e possa perceber que a sociedade gira em torno do conhecimento, do mundo letrado e a escola deve fazer valer a sua função social.

Segundo Nunes (1992), a criança entra na escola em meio a um clima de expectativas no tocante à tarefa de aprender a ler e a escrever, a alfabetização é, sem dúvida, a meta que deve ser alcançada por ela, deixando pais e professores ansiosos. Não se pode desacreditar no sucesso da criança sadia, que ingressa na escola, já sabendo falar, que reconhece objetos, capaz de executar tarefas que coincidem com sua idade cronológica e cognitiva, porém o que deve ser considerado pela família e pelos professores é que ler e escrever requer da criança novas habilidades, habilidades estas que não faziam parte do seu cotidiano até então.

Aprender a ler e a escrever é enfrentar novos desafios em relação ao processo formal de aquisição de conhecimentos. Crianças que apresentam grandes habilidades intelectuais, com certeza terão maiores facilidades para aprender a ler e escreve se forem estimuladas e valorizadas.

A expressão educação infantil e sua concepção com primeira etapa da educação básica está agora na lei maior da educação do país, a Lei de Diretrizes e Bases da Educação Nacional (LDB), sancionada em 20 de dezembro de 1996. Se o direito de 0 a 6 anos à educação em creches e pré - escola já estava assegurada na Constituição de 1988 e reafirmada no Estatuto da Criança e do Adolescente de 1990, a tradução deste direito em diretrizes e normas, no âmbito da educação nacional, representa um marco histórico de grande importância para a educação infantil em nosso país.

A inserção da educação infantil na educação básica, como sua primeira etapa, 
é o reconhecimento de que a educação começa nos primeiros anos de vida e é essencial para o cumprimento de sua finalidade, afirmada no Art. 22 da Lei: "a educação básica tem por finalidade desenvolver o educando, assegurar - lhe a formação comum indispensável para 0 exercício da cidadania e fornecer - lhes meios para progredir no trabalho e nos estudos posteriores".

A educação infantil recebeu um destaque na nova LDB, inexistente nas legislações anteriores. É tratada na Seção II, do capítulo II (Da Educação Básica), nos seguintes termos:

Art. 29 A educação infantil, primeira etapa da educação básica, tem com finalidade $\mathrm{O}$ desenvolvimento integral da criança até os seis anos de idade, em seus aspectos físico, psicológico, intelectual e social, complementando a ação da família e da comunidade.

Art. 30 A educação infantil será oferecida em: I-creches ou entidades equivalentes, para crianças de até três anos de idade; II-pré-escolas para crianças de quatro a seis anos de idade.

Art. $31 \mathrm{Na}$ educação infantil a avaliação far-se-á mediante acompanhamento e registro de seu desenvolvimento, sem o objetivo de promoção, mesmo para o acesso ao ensino fundamental.

Com esse olhar diferenciado para a educação infantil, a escola assume o compromisso de atender as crianças em suas repartições com objetivos definidos e com responsabilidade de colaborar com o processo educativo das crianças proporcionando um ambiente de aprendizagem favorável ao seu nível de idade e seu tempo necessário de aprender de forma lúdica.

\section{Os jogos e brincadeiras na educação da criança}

Desde os mais remotos tempos, o jogo e a brincadeira já faziam parte da vida do ser humano. No início não havia distinção de seu uso pelos adultos e pelas crianças, pois a criança era vista na sociedade como um adulto em miniatura. Suas especificidades não eram consideradas. "No início do século XVII não existia uma separação tão rigorosa como hoje entre as brincadeiras e os jogos reservados às crianças e as brincadeiras e os jogos dos adultos. Os mesmos jogos eram comuns a ambos". (ARIÈS, 1981, p.46)

\section{Jogos e Brincadeiras: Pontuando alguns conceitos necessários}

Os jogos e as brincadeiras são tão antigos que pouco se sabe sobre sua origem, apenas que seus criadores são anônimos e que suas práticas são transferidas para gerações por meio do conhecimento empírico, sendo através da oralidade da criança que sua existência permanece. 
Existem vários significados atribuídos ao termo jogo por diversos autores, mas após algumas consultas na literatura compreendemos o jogo como uma prática social. As crianças aprendem a jogar dentro de um processo histórico construído, ou seja, elas aprendem com os outros componentes de sua cultura, na qual suas brincadeiras são marcadas, pelos conhecimentos, costumes e valores de seu grupo social.

Para Kishimoto (1997 p.17): “[...] enquanto fato social, o jogo assume a imagem, o sentido que cada sociedade lhe atribui. É este o aspecto que nos mostra por que, dependendo do lugar e da época, os jogos assumem significações distintas”.

De acordo com o dicionário Aurélio, a palavra jogo [Do lat. jocu, 'gracejo', 'zombaria', que tardiamente tomou o lugar de ludus.] é uma atividade física ou mental organizada por um sistema de regras que definem a perda ou o ganho. Além disso, é visto como um brinquedo, um passatempo, um divertimento e pode ser também visto como jogo de azar. Já a palavra brincadeira é o ato ou efeito de brincar; significando também divertimento, sobretudo entre crianças, jogo, passatempo, entretenimento.

Segundo Huizinga apud Kishimoto (1998) ao descrevê-lo como elemento da cultura, exclui o jogo dos animais e aponta as características relacionadas aos aspectos sociais: o prazer demonstrado pelo jogador, o caráter "não sério" da ação, a liberdade do jogo e sua separação dos fenômenos do cotidiano, a existência de regras, o caráter fictício ou representativo e a limitação do jogo no tempo e no espaço.

É importante ressaltar que o caráter "não sério" não está relacionado com os aspectos do ato da brincadeira que neste caso é vista como atividade séria, mas com as ações que acompanham o ato lúdico. Podemos então destacar que o jogo é uma atividade voluntária acompanhada de regras explícitas ou implícitas da qual existe a possibilidade de deslocamento da criança da vida cotidiana ao mundo imaginário em um determinado tempo e espaço.

$$
\text { Conforme Kishimoto (1997) os }
$$

autores apontaram características que permitem coligar fenômenos que tem relação com a família dos jogos:

1 - liberdade de ação do jogador ou caráter voluntário, de motivação interna e episódica da ação lúdica; prazer (ou desprazer), futilidade, $\mathrm{o}$ "não sério" ou efeito positivo;

2 - regras (implícitas ou explícitas);

3 - relevância do processo de brincar (o caráter improdutivo), incerteza de resultados;

4 - não literalidades, reflexão de segundo grau, representação da realidade, imaginação e Nesse ponto de vista, entendemos que o jogo permite a criança ser um sujeito ativo, da qual sua atenção está voltada para a atividade em si 
e não em seus efeitos ou resultados.

Ainda para Kishimoto (1998 p.21) a brincadeira:

É a ação que a criança desempenha ao concretizar as regras do jogo, ao mergulhar na ação lúdica. Pode-se dizer que é o lúdico em ação. Desta forma, brinquedo e brincadeira relacionam-se diretamente com a criança e não se confundem com o jogo.

De fato, as ações que a criança desempenha durante a brincadeira serão consideradas como uma interpretação de significados contidos no objeto que ela usa. A brincadeira possui peculiaridades que possibilita a criança ser um sujeito ativo.

A criança dispõe de um acervo de significados. Ela deve interpretálos: a criança deve conferir significados ao brinquedo, durante sua brincadeira. Neste sentido, o brinquedo não condiciona a ação da criança: ele lhe oferece um suporte determinado, mas que ganhará novos significados através da brincadeira. (BROUGÈRE, 2007, p.9).

Durante a brincadeira a criança estará exposta a uma série de objetos e estes conterão significados determinados, o que não impedirá a criança diante das necessidades importar novos significados a estes objetos, pois, de acordo com as indigências durante o desenvolvimento da brincadeira a criança poderá manter de forma voluntária o significado real ou não do objeto.

É importante salientar que:

A brincadeira não pertence à ordem do não-funcional. Por detrás da brincadeira, é muito difícil descobrir uma função que poderíamos descrever com precisão: a brincadeira escapa a qualquer função precisa e é, sem dúvida, esse fato que a definiu, tradicionalmente, em torno das ideias de gratuidade e até de futilidade. E, na verdade, o que caracteriza a brincadeira é que ela pode fabricar seus objetos, em especial, desviando de seu uso habitual os objetos que cercam a criança; além do mais, é uma atividade livre, que não pode ser delimitada. (BROUGÈRE, 2007, p.13-14)

Neste sentido, cremos que a brincadeira não se restringe apenas ao agir, pois os atos da criança têm um significado, que de fato são acirrados pelo o uso do objeto. Percebe-se também que a brincadeira é um ato de relações interindividuais, ou seja, a criança irá aprender a brincar através do meio social em que está inserida. Brougère (2007 p.102-103) explica que "a brincadeira é um espaço social, uma vez que não é criada espontaneamente, mas em consequência de uma aprendizagem social e supõe uma significação conferida por todos que dela participam (convenção)".

Desta maneira, considera-se importante enfatizar que a brincadeira será 
um sistema sequencial de decisões e onde sua permanência ocorre dentro de um determinado tempo e espaço. De fato, esse sistema irá se exprimir através de um conjunto de regras, que poderão ser explícitas ou implícitas. Sendo importante destacar que tais regras só terão validade durante a brincadeira e se forem acolhidas pelos membros que a compõem.

Sendo importante ressaltar que a distinção dos jogos e das brincadeiras, não poderá ser marcada apenas pela existência ou não de regras, o que irá determinar a diferenciação de ambas será a existência de um vencedor que no caso só acontece no jogo. Como enfatiza Funicelli (2008 p.17): "Quando se tem uma situação imaginária e regras tem-se uma brincadeira; se a situação é imaginária; há regras e um vencedor, temse o jogo".

De acordo com Brougère (2007 p. 103):

A brincadeira possui uma dimensão aleatória. Nela encontramos o acaso ou a indeterminação, resultantes da complexidade das causas que estão em ação. É um espaço que não pode ser totalmente dominado de fora. Toda coação interna faz ressurgir a brincadeira... Toda coação externa arrisca-se a destruíla.

Dessa forma, entendemos que a criança brinca com os instrumentos que possui sendo necessária orientação quanto a forma de brincar. Os estímulos devem existir, para que o interesse não acabe, nem haja tempo para substituir as brincadeiras por atividades monótonas e que não estimulem a criatividade e ludicidade.

\section{Jogos e brincadeiras na escola}

Muitas vezes a brincadeira é tida na escola como tempo perdido, tal fato pode ter surgido da concepção de que a brincadeira é uma atividade oposta ao trabalho, tornando ela menos importante, porém, na prática isso tem provocado a diminuição dos ambientes e do tempo do brincar. Tornando a hora do recreio um espaço reservado excepcionalmente para a criança brincar com o objetivo, no entanto, de repor energia para o trabalho que é visto como a única atividade séria. (BORBA, 2006)

Vygotsky (1998) esclarece que o aprendizado e o desenvolvimento estão inter-relacionados desde o nascimento da criança, ou seja, o aprendizado da criança inicia antes dela frequentar a escola, o que é designado de aprendizado pré-escolar não sistematizado. No entanto, ao ingressar na escola surge o aprendizado escolar ou sistematizado. O que diferencia do outro é o fato da apropriação de conhecimentos científicos que irá causar algo novo no desenvolvimento da criança. Neste mesmo sentido Freire (1992 p.21) destaca que "a 
escola precisa perder a ilusão de que ela é a única que está ensinando o que é necessário para se viver em sociedade".

Cabe à escola incluir em suas dinâmicas pedagógicas e dentro de sua estrutura física, ações que propiciem a motivação das crianças, possibilitando o desenvolvimento da autonomia nas expressividades, ou seja, na qual respeite a condição de a criança ser vista como ser integral e único. Wallon (apud Mahoney e Almeida, 2007 p. 17) explica que "é contra a natureza tratar a criança de forma fragmentária. Em cada idade constitui um conjunto indissociável e original. $\mathrm{Na}$ sucessão de suas idades é um único e mesmo ser em contínua metamorfose".

Os jogos e as brincadeiras estabelecem especificamente às crianças um espaço de inovação onde permite o alargamento de habilidades físicas, mentais e sociais. De fato, por meio dos jogos e das brincadeiras as crianças interagem com o meio que a cerca, contribuindo dessa forma para o desenvolvimento de seus sentimentos e emoções. Ao brincar a criança expressa de que forma ela entende e se relaciona com o mundo, sendo ele considerado um recurso que ela dispõe para expressar-se e para desenvolver-se com a existência harmoniosa do corpo e da mente em sociedade.
O jogo é usado pelo educador como uma forma de estimular o desenvolvimento físico e intelectual da criança, possibilitando-lhe estabelecer novos conhecimentos e a ampliar os conhecimentos já adquiridos. Como enfatiza Funicelli (2008 p.7):

O emprego desta ferramenta
permite ao professor não apenas a
possibilidade de aferição da
assimilação de conteúdos pelo
aluno. Trata-se de uma ponte para
o espectro subjetivo da criança, em
que pode ser verificado como cada
sujeito se relaciona com o
aprender.

Portanto, o uso dos jogos e das brincadeiras permite à criança estar em constante desafio, favorecendo a ampliação de novas habilidades. A presença do uso dos jogos e brincadeiras também oferece ao professor subsídio para averiguar de que forma está ocorrendo o processo de ensinoaprendizagem. Além disso, permite observar a relação criada pela criança com $\mathrm{o}$ ato de aprender.

Durante o desenvolvimento de atividades lúdicas, as ações, falas, movimentos entre outros aspectos devem ser vistos pelo educador como um meio que torna possível averiguar a constituição de novas aprendizagens ou a reconstituição de aprendizagens já existentes.

No entanto Borba (2006 p.39) enfatiza que "os processos de 
desenvolvimento e de aprendizagem envolvidos no brincar são também constitutivos do processo de apropriação de conhecimento!". Ou seja, será durante a brincadeira que a criança terá chance de dar novas definições ou de constituir relações inseridas em um contexto simbólico para os elementos físicos e sociais do meio real que a cerca. Permitindo dessa forma, que a criança se aproprie de conhecimentos que favorecerão o desenvolvimento da cognição.

Considerando que a criança começa a constituir aprendizagens assim que nasce e continua adquirindo conhecimento à medida que se desenvolve e se relaciona com o meio que ela faz parte, essas aprendizagens iniciais servirão como ponto de referência durante o seu desenvolvimento.

O professor, em busca de favorecer o desenvolvimento cognitivo da criança, provoca avanços que não ocorriam de forma espontânea, mas que poderão ser provocados através do uso dos jogos e das brincadeiras. Como explica Vygotsky (1998 p.118):

Aprendizado não
desenvolvimento; entretanto, o
aprendizado adequadamente
organizado resulta em
desenvolvimento mental e põe em
movimento vários processos de
desenvolvimento que, de outra
forma, seriam impossíveis de
acontecer. Assim, o aprendizado é

um aspecto necessário e universal do processo de desenvolvimento das funções psicológicas culturalmente organizadas e especificamente humanas.

Outro ponto importante do uso dos jogos e brincadeiras é a questão da corporeidade dentro e fora da sala de aula, pois esta vem acompanhada de fatores que cooperam para o processo de ensino e aprendizagem numa perspectiva holística e sistêmica.

Por meio de observações do uso das brincadeiras e a forma organizacional em que a criança desempenha durante o ato do brincar, percebe-se a expressividade de fatores relacionados a sua vivência. Através da brincadeira a criança reproduz e representa o mundo. Tais circunstâncias permitirão à criança uma reflexão sobre si e o mundo que a cerca. Contribuirão dessa forma, para a construção e a reconstrução de novos significados. Como explica Borba (2006, p.33):

A criança, pelo fato de se situar em um contexto histórico e social, ou seja, em um ambiente estruturado a partir de valores, significados, atividade e artefatos construídos e partilhados pelos sujeitos que ali vivem, incorpora a experiência social e cultural do brincar por meio das relações que estabelece com os outros - adultos e crianças. Mas essa experiência não é simplesmente reproduzida, e sim recriada a partir do que a criança traz de novo, com seu poder de 
imaginar, criar, reinventar e produzir cultura.

Neste contexto, percebe-se a importância do uso do jogo simbólico, pois este possibilita a criança vivenciar fatos marcantes do meio real em que ela faz parte, como também situações almejadas, penosas, passadas e futuras. Inicialmente, o recurso utilizado será o uso de objetos acompanhados de gestos, verbalizações e expressões já vivenciadas pelas crianças.

À medida que a criança se desenvolve, torna o uso do objeto desnecessário, permanecendo apenas a existência das ideias, imagens e regras estabelecidas. De fato, a imitação torna-se importante porque ela é uma reconstrução de situações vivenciadas, ou seja, aquilo que ela imita atualmente com auxílio, no futuro poderá fazer sozinha, criando-se o que Vygotsky chama de Zona de Desenvolvimento Proximal. Entretanto, Vygotsky também faz referência aos conceitos de zona de desenvolvimento real e a zona de desenvolvimento potencial.

Quando a criança já consegue desenvolver uma atividade por sim só, ou seja, de formas independentes seu nível de desenvolvimento já atingiu o que Vygotsky denomina de zona de desenvolvimento real.

Zona de desenvolvimento real: refere-se "aquelas conquistas que já estão consolidadas na criança, aquelas funções ou capacidades que ela já aprendeu e domina, pois já consegue utilizar sozinha, sem assistência de alguém mais experiente da cultura (pai, mãe, professor, crianças mais velha etc.) Este nível indica, assim, os processos mentais da criança que já estabeleceram, ciclos de desenvolvimento que já se completaram. (REGO, 1995. p. 73-4 apud SAUER, 2002 p. 52).

No entanto, de acordo com Vygotsky a zona de desenvolvimento potencial corresponde ao período em que a criança ainda demonstra uma certa dependência nas realizações de atividades, ou seja, ela necessita do auxílio de outra pessoa para conquistar determinado objetivo.

Zona de desenvolvimento potencial: "refere-se aquilo que a criança é capaz de fazer, só que mediante a ajuda de outra pessoa (adultos ou crianças mais experientes). Nesse caso, a criança realiza tarefas e soluciona problemas através do diálogo, da colaboração, da imitação, da experiência compartilhada e das pistas que lhe são oferecidas. (...) Este nível é, para Vygotsky, bem mais indicativo de seu desenvolvimento mental do que aquilo que ela consegue fazer sozinha". (REGO, 1995. p. 73-4 apud SAUER, 2002 p. 52).

Já a zona de desenvolvimento proximal é compreendida como uma distância existente entre o que a criança já consegue fazer independente e o que ela só 
consegue realizar mediante a ajuda de outra criança ou até mesmo um adulto, mas que poderá atingir em curto prazo.

Zona de desenvolvimento proximal: "a distância entre aquilo que ela é capaz de fazer de forma autônoma (nível de desenvolvimento real) e aquilo que ela realiza em colaboração com os outros elementos do seu grupo social (nível de desenvolvimento potencial) caracteriza aquilo que Vygotsky chamou de "zona de desenvolvimento proximal”. Neste sentido, o desenvolvimento da criança é visto de forma prospectiva, pois a "zona de desenvolvimento proximal define aquelas funções que ainda não amadureceram que estão em processo de maturação, funções que amadurecerão, mas que estão presentes em estado embrionário". Essas funções poderiam ser chamadas de "brotos" ou "flores" do desenvolvimento" (Vygotsky, 1984, p.97). Deste modo, pode-se afirmar que o conhecimento adequado do desenvolvimento individual envolve a consideração do nível de desenvolvimento real quanto do potencial" (REGO, 1995. p. 73-4 apud SAUER, 2002 p. 52).

O jogo tem sido considerado um instrumento que pode auxiliar o educador na ampliação de atividades que colabora com o desenvolvimento integral da criança, ocasionando assim avanços no seu processo de aprendizagem. Será através das brincadeiras e dos jogos que a criança aprenderá a coordenar seus movimentos e constituir seus limites, beneficiando em equidade, no crescimento de fatores cognitivos, afetivos e perceptivos.

No decorrer do jogo as trocas de experiências beneficiarão o conhecimento e a afetividade, estes irão consolidar uma relação significativa, que contribuirá para o surgimento da aprendizagem na criança.

Para isso, é necessário que o professor selecione os materiais necessários, buscando utilizá-los de acordo com a faixa etária e com os objetivos que se pretende alcançar. É preciso procurar deixar tudo exposto, de forma que a criança tenha autonomia durante as escolhas dos materiais que farão parte da brincadeira. Como explica Porto (2008, p.7):

Para compreender o que está em jogo quando a criança brinca, se faz necessário analisar o suporte material e imaterial que desencadeia tal ato, o ambiente, os momentos a ele destinados e as pessoas que dele participam, pois as crianças precisam de tempo, espaço, companhia e material para brincar. Quanto mais elas possam ver, ouvir ou experimentar, quanto mais consigam aprender e assimilar, quanto mais elementos reais estejam disponíveis em suas experiências, tanto mais considerável e produtiva será a atividade de sua imaginação.

Compreende-se dessa forma que a brincadeira favorece ao desenvolvimento. Por interferência dela, a criança apropriarse de conhecimento que beneficiará para a construção e reconstrução de novos 
conceitos, permitindo, assim, que a criança solucione situações-problemas do seu meio social.

As afinidades que as crianças evidenciam durante a brincadeira ou no jogo, possibilitam constituir uma relação de afetividade, que são estabelecidas pela capacidade da criança produzir e reproduzir suas emoções durante a ação. Tal acontecimento conduz a criança para um mundo de descobertas.

A presença dos jogos e brincadeiras nas atividades pedagógicas deve possibilitar uma afinidade com o processo ensinoaprendizagem, pois ao estar inserida em um momento lúdico a criança dispõe de liberdade de pensamento e de ação. Este momento permite que a criança use intensamente $\mathrm{o}$ afeto, conduzindo às descobertas.

Segundo Piaget (1991, p. 1):

É incontestável que o afeto exerce um papel essencial no funcionamento da inteligência. Sem o afeto não haveria interesse, necessidade, motivação $\mathrm{e}$ consequentemente, não haveria inteligência. A afetividade é uma condição necessária na constituição da inteligência, mas (...) não é suficiente.

Através da brincadeira e do jogo a criança pode demonstrar sua angustias, medos, agressividades entre outros sentimentos, pois a espontaneidade e envolvimento permitem a exposição dos sentimentos e emoções.

Sendo o movimento visto como uma forma de comunicação, interação e pensamento, será por meio da brincadeira que a criança terá a oportunidade desenvolver suas potencialidades. Por isso, é importante que as instituições acreditem e tornem real que a educação da criança seja de corpo inteiro.

\section{Tipos de jogos e brincadeiras}

Diversos autores estabelecem uma classificação dos jogos e brincadeiras que seguem determinados critérios, dentre estes Kishimoto para a qual os jogos e brincadeiras são classificados em: jogos de exercícios sensório motores; jogos e brincadeiras simbólicas; brincadeiras de construção; jogos e brincadeiras tradicionais; jogos de regras. No entanto, faz-se necessário esclarecer a importância de alguns para o desenvolvimento da criança.

Os jogos de exercícios sensórios motores são os primeiros que iniciam na vida do ser humano pela necessidade do prazer e permanecem até o surgimento da linguagem. No entanto, o prazer conduzirá o significado para a ação. A concretização desse jogo consiste em repetições de movimentos e gestos simples desempenhados pelas crianças como: 
erguer os braços e pernas; arrastar para alcançar um objeto; arremessar brinquedos; balbuciar para imitar sons dos adultos; saltar em cima de pneus; correr, entre outros.

De acordo com Brougère (2007 p.98):

A brincadeira pressupõe uma aprendizagem social. Aprende-se a brincar. A brincadeira não é inata, pelo menos nas formas que ela adquire junto ao homem. A criança pequena é iniciada na brincadeira por pessoas que cuidam dela, particularmente sua mãe.

Os jogos e brincadeiras simbólicas, conhecidos também como brincadeira de faz-de-conta, incidem por volta de dois aos seis anos. Despertam na criança o aparecimento da representação e da linguagem, ou seja, ela tem a capacidade de produzir imagens mentais e domínio na linguagem que permite a criança criar símbolos para a substituição de objetos. Através do uso dos objetos, a criança reproduz situações vivenciadas em seu meio social ou constrói situações desejáveis, ou seja, o objeto desempenha a função de fornecer sentido às ações realizadas pelo infante.

No entanto Freire (1992, p.43) explica que:

Durante $o$ ato de imaginar, nada se interpõe à fantasia infantil mas, durante a ação corporal que o acompanha, verifica-se uma busca de ajustamento ao mundo exterior, uma espécie de acomodação, para usar um termo piagetiano. Por outro lado, a ação imaginada não tem origem na mente apenas, mas na relação concreta da criança com o mundo.

A respeito de o simbólico no brincar Brougère (2007, p.105) ressaltar que: "a criança não brinca numa ilha deserta. Ela brinca com as substâncias materiais e imateriais que lhe são propostas. Ela brinca com o que tem à mão e com o que tem na cabeça. Os brinquedos orientam a brincadeira, trazem-lhe a matéria".

As brincadeiras de construção são importantes pela capacidade de possibilitar a criança aptidões que contribuam para o alargamento da criatividade e de aptidões sensório-motoras. Apesar disso, o jogo de construção possui uma relação estreita com o jogo de faz-de-conta, pois na medida em que a criança constrói com os bloquinhos, ela procura criar um cenário para $o$ desenvolvimento da brincadeira simbólica. No entanto, se faz necessário que o educador considere tanto as falas realizadas durante as construções como as ações das crianças, no intuito de abarcar a forma que os infantes elegem a temática e a forma que o meio que acerca intervém.

A origem dos jogos e brincadeiras tradicionais é desconhecida, sabe-se apenas que sua existência tem sido por meio da 
comunicação, os costumes, valores e os ensinamentos transmitidos de geração em geração. Tal fato torna os jogos e brincadeiras tradicionais como um patrimônio lúdico-cultural. Entretanto, a utilização dessas brincadeiras coopera para o alargamento das aptidões, corporais, sociais, afetivas e cognitivas das crianças.

\section{METODOLOGIA BIBLIOGRÁFICA}

\section{Características da pesquisa}

Trata-se de uma pesquisa bibliográfica com intensa leitura dos textos e obras, sistematizado por Lessa (2011, p. 20 e 21) "A leitura imanente consiste na decomposição do texto em suas unidades significativas mais elementares: ideias, conceitos, categorias, na busca da trama que articulava tais unidades a uma teoria, hipóteses, teses e proposições, com o intuito de elaborar outras teorias interpretativas".

A Leitura Imanente é um recurso que nos ajuda em estudos sistemáticos de pesquisas acadêmicos, encontrados em forma de livros, teses, dissertações, monografias, artigos, entre outros; bem como em estudos bibliográficos. A utilização e aplicação consecutiva e crítica desta metodologia aperfeiçoa o campo cognitivo que abrange a compreensão e a apreensão dos elementos que estruturam os modos de exprimir e materializar os
Já os jogos de regras revelassem no infante por volta dos quatro a sete anos, ampliando-se apenas dos sete a onze anos. Ao renunciar o egocentrismo, as crianças procuram supri-lo através da inclusão de atividade onde as regras possuem um determinado aproveitamento afetuoso, possibilitando a experiência de cooperação entre os membros que compõe o jogo.

conhecimentos científicos (BEZERRA, 2015).

De acordo com Vieira (2006, p. 17), “a pesquisa bibliográfica fundamenta-se principalmente em análises qualitativas, baseadas em conhecimentos teóricoempíricos que permitem atribuir-lhes cientificidade".

\section{Do ponto de vista dos objetivos}

No que diz respeito aos meios, em relação à abordagem dos objetivos, esta pesquisa é exploratória, que tem a finalidade de proporcionar familiaridade com o problema, tornando-o explícito ou, ainda legitimando a construção de hipóteses (GIL, 2010).

De acordo com o autor acima citado o primordial objetivo da pesquisa exploratória deve ser o aprimoramento das ideias ou a descoberta das instituições. 
Do ponto de vista dos procedimentos técnicos e da abordagem do problema

As metodologias técnicas utilizadas para este estudo foi o levantamento bibliográfico e documental tem por objetivo proporcionar familiaridade com o problema, tornando-o mais explicitado (LAKATOS; MARCONI, 2001).

Por meio das pesquisas realizadas, de modo sistematizado, em livros, artigos

\section{RESULTADOS E DISCUSSÕES}

Pode-se afirmar que o lúdico é qualquer atividade que executamos e que pode dar prazer, que tenhamos espontaneidade em executá-la. Nesse sentido, na visão de Bertoldo (2011), quando fazemos porque queremos, pôr interesse pessoal. Isto se refere tanto à criança quanto para o adulto, é aí que começamos a perceber a possibilidade, a facilidade de se aprender, quando estamos brincando, pois na atividade lúdica, como na vida, há um grande número de fins definidos e parciais, que são importantes e sérios, porque consegui-los é necessária ao sucesso e, consequentemente, essencial a satisfação que o ser humano procura, a satisfação oculta, neste caso seria o de aprender.

Nesse sentido, o lúdico vem ganhando atenção no meio acadêmico pela crescente quantidade de contribuiçõos para científicos, disponíveis em documentos impressos e também em bases de dados virtuais reconhecidas, foram possíveis expandir o conhecimento em torno dos temas que cercam este estudo, ajudando deste modo para uma fundamentação teórica capaz de embasar a procura para atender aos objetivos propostos e responder de modo eficaz o questionamento da pesquisa.

a sua conceituação e reflexão, mas poucos têm constatado, sua aplicação e sistematização enquanto ferramenta pedagógica, visto que, através das atividades lúdicas, as crianças adquirem marcos de referenciais significativos que lhes permitem conhecer a si mesmas, descobrir o mundo dos objetos e o mundo dos outros, experimentando também, situações de aventura, ação e exploração, como características impostergáveis da infância.

Assim, Wayskop (1995) destaca que com o jogo, as crianças fixam convicções de justiça, solidariedade e liberdade. São resolvidas situações problemáticas, adaptando-se de forma ativa a sociedade em que vivem. Portanto, Marcellino (1997, p.44) destaca que "ao tratar do lúdico foca a abordagem que se busca, o lúdico não como algo isolado ou associado a uma determinada atividade", mas como um componente cultural historicamente situado 
que pode transcender aos momentos de lazer, como seu uso na Educação: "porque não atuar com os componentes lúdicos da cultura, em outras esferas de obrigação, notadamente... na escola?"

As instituições de Educação Infantil têm restringido as atividades das crianças aos exercícios repetitivos, motora e, ao mesmo tempo em que bloqueiam a organização independente das crianças para as brincadeiras, essas práticas não estimulam a criatividade dos alunos, como se suas ações simbólicas servissem apenas para explorar e facilitar ao educador a transmissão de determinada visão do mundo, definida, a princípio, pela instituição infantil.

Nessa perspectiva, Wayskop (1995) aponta que se as instituições fossem organizadas em torno do brincar infantil, elas poderiam cumprir suas funções pedagógicas, privilegiando a educação da criança em uma perspectiva criadora, voluntária e consciente

De acordo com o pensamento de Soler (2003) não se pode mais conceber que uma pessoa que passa pela escola saia sem entrar em contato com valores humanos essenciais, e que depois, fora da escola, comete atos grotescos, pois, a escola deve ensinar para além da Matemática, Língua Portuguesa, Educação Física, enfim, deve ensinar a pessoa a ser feliz e fazer as outras pessoas felizes.

Dessa forma, resgatar a ludicidade dentro de um processo educativo, é ir a busca da construção de bases para: através de práticas e vivências, possibilitar que este indivíduo modifique seu foco de atenção e consiga enxergar além da realidade das sombras, como afirmava Platão e possa vislumbrar a possibilidade de desenvolver plenamente suas potencialidades.

De acordo com Gomes (2004, p.47), a ludicidade é uma dimensão da linguagem humana, que possibilita a "expressão do sujeito criador que se torna capaz de dar significado à sua existência, ressignificar e transformar o mundo". E mais na frente conclui: "Dessa forma, a ludicidade é uma possibilidade e uma capacidade de se brincar com a realidade, ressignificando o mundo" (GOMES, 2004, p. 145). Ainda falando do lúdico, Gomes nos dá a chave para estabelecer a premissa básica de nossa abordagem quando escreve:

Como expressão de significados que tem o brincar como referência, o lúdico representa uma oportunidade de (re) organizar a vivência e (re) elaborar valores, os quais se comprometem com determinado projeto de sociedade. Pode contribuir, por um lado, com a alienação das pessoas: reforçando estereótipos, instigando discriminações, incitando a evasão da realidade, estimulando a passividade, $\mathrm{o}$ 
conformismo e o consumismo; por outro, o lúdico pode colaborar com a emancipação dos sujeitos, por meio do diálogo, da reflexão crítica, da construção coletiva e da contestação e resistência à ordem social injusta e excludente que impera em nossa realidade. (GOMES, 2004, p. 146)

Portanto, sabe-se que a ludicidade é uma necessidade em qualquer idade e não pode ser vista apenas como diversão. O desenvolvimento do aspecto lúdico facilita a aprendizagem, o desenvolvimento pessoal, social e cultural, colabora para uma boa saúde mental, prepara um estado interior fértil, facilita a comunicação, expressão e construção do conhecimento. Assim, a prática lúdica entendida como ato de brincar das crianças permite um mergulho na sua trajetória ao longo dos

\section{CONSIDERAÇÕES FINAIS}

Os obstáculos encontrados na educação do país hoje se devem a vários fatores, entre eles a ausência de políticas de incentivo com repercussão direta na qualidade do ensino, promovendo melhoria nas condições de trabalho dos profissionais da educação, indo da qualificação continuada ao pagamento de salários que ajudem a dignificar a carreira docente.

Constatou-se nesta pesquisa a importância da aplicação do lúdico como instrumento facilitador da aprendizagem da matemática uma vez que o estudo tempos, acumulando informações. A esse respeito, Santos (2008) menciona que este processo cíclico, retratado em cada ação e em cada jogo, permite conhecer um pouco da evolução. Portanto, entender o brincar das crianças no cenário das civilizações é conhecer um pouco da cultura.

Com isso, a Educação pela vida da ludicidade propõe-se a uma nova postura existencial cujo paradigma é um novo sistema de aprender brincando, inspirando numa concepção de educação para além da instrução. Para que isso aconteça é preciso que os profissionais da educação reconheçam o real significado do lúdico para aplica-lo adequadamente, estabelecendo a relação entre o brincar e o aprender.

evidenciou a necessidade que estimulem o aprendizado na disciplina bem como a crença positiva dos frutos que podem gerar a implantação correta desse instrumento. Diante disso, a presente pesquisa buscou delinear um estudo que demonstra a percepção dos docentes com relação à importância do lúdico, levando-se em consideração os professores da Educação Infantil e Fundamental I. De acordo com a pesquisa, a atividade lúdica é explorada sem um planejamento estratégico definido, sem uma coerência de atividades e sem qualquer incentivo por parte da administração seja 
ela Estadual, Municipal ou Privada; fato que dificulta o desenvolvimento eficiente desse método. Em se tratando dos docentes dos ensinos acima citados.

Conclui-se que o lúdico é usado nas escolas, mas de forma não sistemática, o que certamente implicaria benefícios no desenvolvimento e na eficiência da metodologia, assim como na eficácia da avaliação da aprendizagem. Em se tratando da percepção da relevância do lúdico para o ensino o estudo constatou que existem muitos paradigmas a serem quebrados uma vez que não existindo a aplicação correta do método do estudo torna-se difícil uma percepção visível e concreta da eficácia produzida pela adoção da pratica lúdica em sala de aula.

Partindo desta análise, percebemos que professores e conselhos escolares poderiam incluir no calendário com base no uso da atividade lúdica como instrumento de auxílio a aprendizagem, objetivando preparar melhor os docentes para etapas futuras que exigem uma boa educação de

\section{REFERÊNCIAS}

ALMEIDA, P. Língua Portuguesa e ludicidade: ensina brincando não é brincar de ensinar. São Paulo, 2007, 130p. Dissertação (Mestrado) - Pontifícia Universidade Católica de São Paulo.

ARIÈS, P. História Social da Criança e da Família. 2. ed. Rio de Janeiro: Guanabara, 1981. base para o sucesso na carreira profissional. A inclusão do lúdico é relevante, na medida em que será uma busca para a diminuição de altos índices de péssimo desempenho de alunos diante de provas nacionalmente reconhecidas. Por fim, recomendamos aos profissionais atuantes da área a adoção de medidas que minimizem as deficiências dos discentes. Novas propostas sempre estimulam e podem ser casos de grande sucesso, se aplicadas com o devido cuidado e seguindo um bom planejamento.

Para pesquisas posteriores, sugerimos aumentar o universo da pesquisa sobre o lúdico direcionado para outros níveis escolares, de maneira que possa ser utilizado como recurso facilitador da aprendizagem. Outro estudo comparativo pode ser realizado com outras disciplinas, ou mesmo com outro nível escolar. Sugerimos ainda a aplicação da atividade lúdica com professores e alunos, no intuito de verificar as atribuições dos docentes e o nível de conhecimento dos alunos depois da adoção dessa metodologia.

BERTOLDO, J.V; RUSCHEL, M. A. M. Jogo, brinquedo e brincadeira - Uma Revisão Conceitual. Disponível em: http://www.ufsm.br/gepeis/jogo.htm. Acesso no dia 02 de mar. de 2011.

BRASIL, LDB - Lei de Diretrizes e Bases da Educação Nacional. Lei no 9.394/96 de 20 de dezembro de 1996. 
BROUGÈRE, G. Brinquedo e Cultura. São Paulo: Cortez, 2007.

FREIRE, Paulo. Pedagogia da autonomia: saberes necessários à prática educativa. São Paulo: Paz e Terra 1992.

GOMES, C. L. (org.). Dicionário Crítico do Lazer. Belo Horizonte: Autêntica, 2004.

KISHIMOTO, T. M. O brinquedo na educação: considerações históricas. Ideias, o cotidiano da pré-escola. São Paulo, n.7, p.39-45, 1997. Fundação para o

Desenvolvimento da Educação.

MARCELLINO, N. C. Pedagogia da animação. 2. edição, Campinas, São PauloSP, Editora Papirus, 1997.

PIAGET, J. A psicologia da criança. Ed. Rio de Janeiro. Bertrand Brasil, 1991.
SOUER, R. Jogos cooperativos para a educação infantil. Rio de Janeiro: Sprint, 2002.

SMITH, C.; STRICK, L. Dificuldades de aprendizagem de a z: um guia completo para pais e educadores. Tradução de Dayse Batista. Porto Alegre: Artmed, 2001.

SOLER, R. Jogos cooperativos para a educação infantil. Rio de Janeiro: Sprint, 2003.

TAVARES, C. F. Curiosidade: uma aliada na aprendizagem. Revista do Professor. Rio Pardo: CPOEC. № 45. p. 31-32, janeiro/março, 1996

VYGOTSKY, L. S. Aprendizagem, desenvolvimento e linguagem. 2. ed. São Paulo: Ícone, 1998.

WAJSKOP, G. Brincar na Pré-Escola. São Paulo: Cortez, 1995 